\title{
INSIGHTS ON INDUSTRY ENGAGEMENT FROM MARINE RECREATIONAL USE STUDIES IN THE NORTHEAST U.S.
}

Best Practices, Lessons, and Applications for Human Use Characterization in Marine Spatial Planning

August 2016
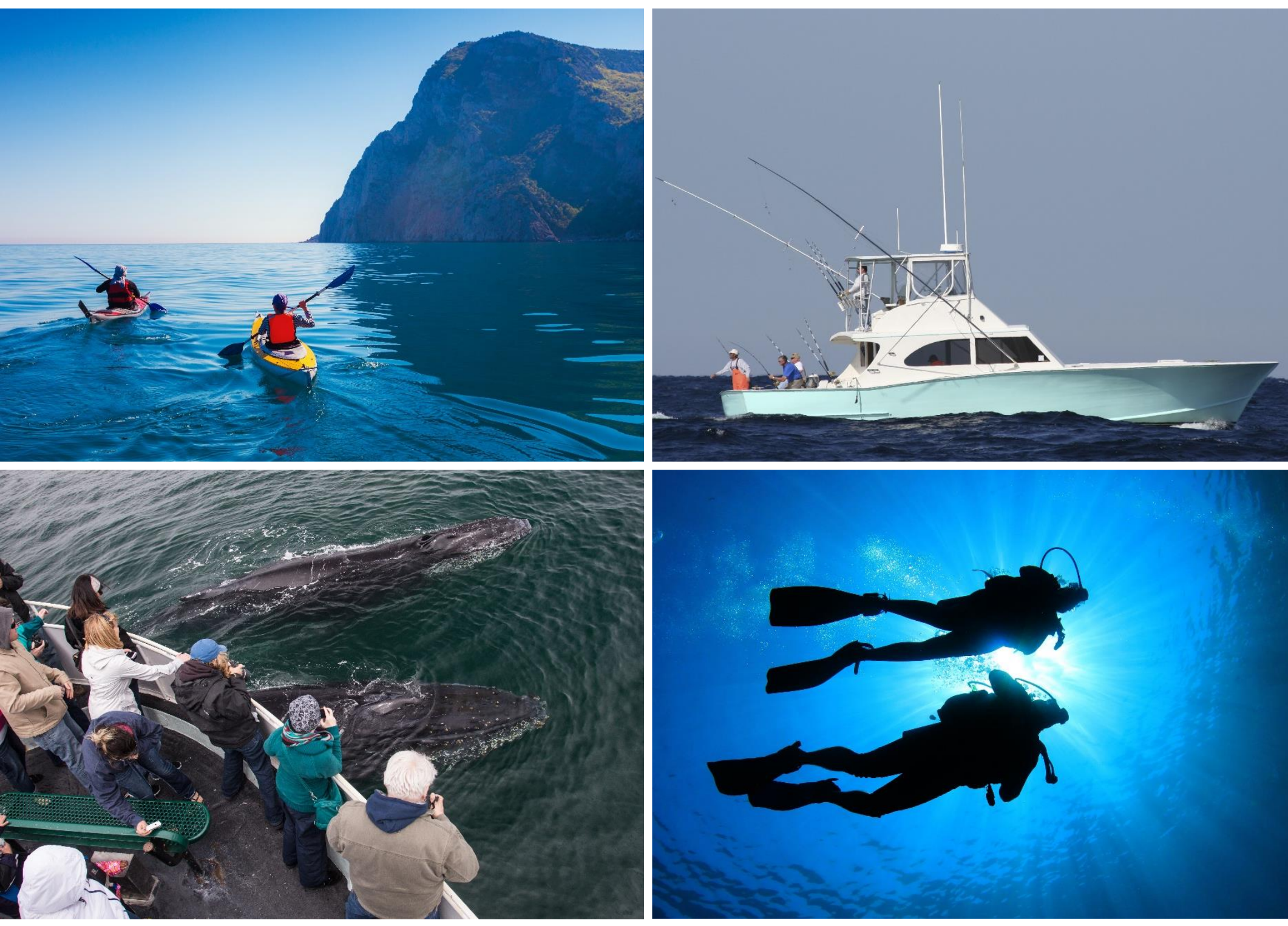

Prepared by:

Kate Longley-Wood, Senior Project Manager Andrew Lipsky, Senior Partner Stephanie Moura, Managing Partner 


\section{EXECUTIVE SUMMARY}

For the past decade, state and regional ocean planning authorities across the United States have been designing and conducting integrated and comprehensive marine planning processes in accordance with national, regional, and state mandates or guidance. Understanding and characterizing a variety of human uses of the ocean through combined data collection and stakeholder engagement initiatives is a core component of these processes.

Marine recreation has been a primary focus for these efforts, largely because there is a general lack of data characterizing this sector, despite its significant social and economic importance. Planning and management authorities as well as marine industry stakeholders have recognized this data gap. To fill this gap, planning authorities have been working closely with marine recreational industry leaders and experts on a number of studies which have resulted in datasets that are relevant to planning and management agencies and are also considered trustworthy by the industries. While these studies have employed a variety of approaches, techniques, and tools to characterize a diverse set of marine industries, a number of common themes and observations have emerged. This paper highlights these overarching best practices and insights distilled from SeaPlan's experience with collaborative marine human use characterization studies in the Northeastern U.S.

These common methodological best practices and strategies are framed within a collaborative data collection and engagement model developed and adapted through designing and conducting successive marine recreational use studies between 2009-2016. Employing this collaborative model was instrumental in generating trusted data credible to all parties and creating an avenue for direct industry participation in the ocean planning process. We also offer two key strategies which can be used within the model's framework. The first frames data as a shared asset, where information is intentionally developed to meet planning, management, and industry goals simultaneously. The second strategy encourages engagement approaches which are tailored toward unique industry characteristics, such as geographical distribution, seasonality, and existing industry organization.

This paper presents four case studies which demonstrate how the collaborative model's best practices and associated strategies have been put into practice in the Northeastern U.S. over the past seven years. These studies include the 2010 Massachusetts Recreational Boater Survey, the 2012 Northeast Recreational Boater Survey, the 2015 Northeast Coastal and Marine Recreational Use Characterization Survey, and the 2013-2016 Pilot Charter and Party Vessel Fishing Mapping Project. Reflecting on the outcomes of these studies, we present a summary of lessons learned from this body of work. The intent in sharing this experience is, specifically, to inform others' efforts as existing marine plans are implemented and as other regions and states embark on similar marine industry characterizations, and, more broadly, to contribute to the growing body of work in marine social sciences. 


\section{TABLE OF CONTENTS}

Executive Summary . i

Table of Contents ii

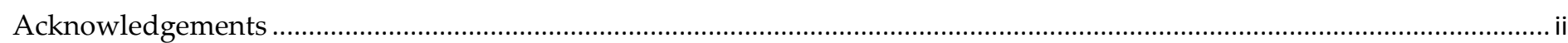

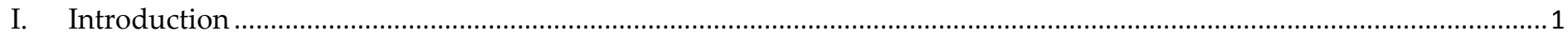

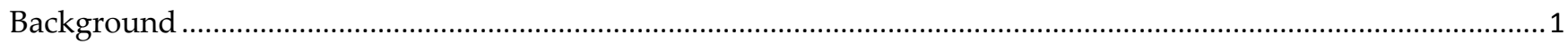

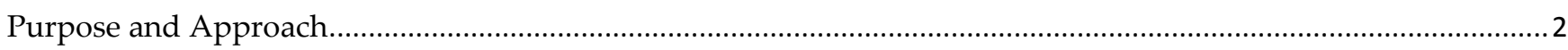

II. A Collaborative Data Collection and Engagement Model and Key Strategies .......................................................

The Collaborative Data Collection and Engagement Model.....................................................................................

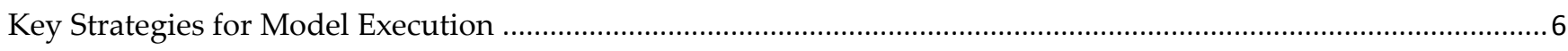

III. Marine Recreational Use Characterization Case Studies ...................................................................................

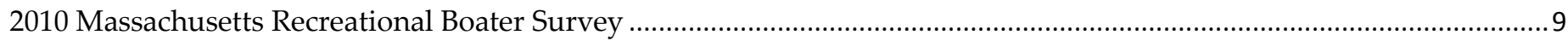

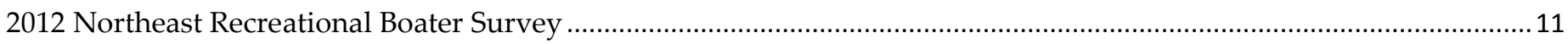

2015 Northeast Coastal and Marine Recreational Use Characterization Survey ……........................................................14

2013-2016 Pilot Charter and Party Vessel Fishing Mapping Project................................................................................ 18

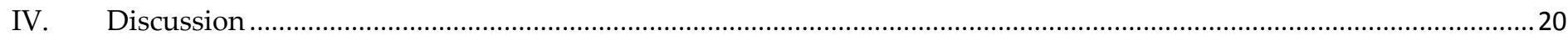

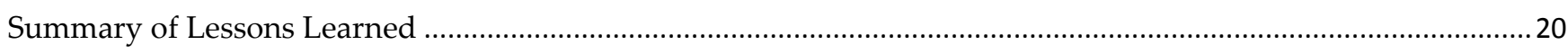

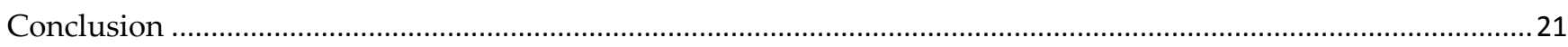

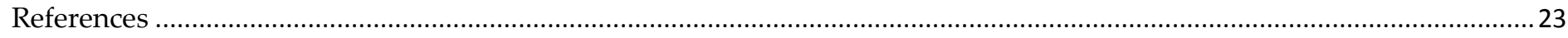

\section{ACKNOWLEDGEMENTS}

The efforts and outcomes of the projects described in this paper would not have been possible without the hard work and thoughtful contributions of all projects partners, which include members of state and federal agencies, industry partners, individual contributions of industry members, and technical consultants. SeaPlan staff Molly Morse (Project Associate II), Peter Zaykoski (Project Manager), and Ian Mogavero (Deputy Director) provided invaluable assistance with content contributions, review, and document preparation. 


\section{INTRODUCTION}

\section{BACKGROUND}

For the past decade, state and regional ocean planning authorities across the U.S. have been designing and conducting integrated and comprehensive marine planning processes in accordance with national, regional, and state mandates or guidance. These processes require an understanding of both marine ecosystems and the human uses that interact with these ecosystems. To that end, the National Ocean Policy underscored the importance of integrating human dimensions of the marine environment into management decision-making and the application of social science approaches to better characterize marine human uses, particularly for understudied sectors (CEQ 2010). Partly due to the relative dearth of data about marine recreation, this sector has emerged as a major focus area for efforts to gain a thorough understanding of past, current, and potential future human uses of the ocean.

Economically, marine tourism and recreation is a highly significant sector. It comprises the largest number of jobs in the ocean economy, and generates over $\$ 100$ billion of the GDP (NOEP 2009, NOEP 2014, NOEP 2016). Despite the fact that marine recreation is geographically widespread and spans a range of industries and activities, including recreational boating, fishing, whale watching, diving, beach-going, paddle sports, and marine recreational events (e.g., sailing regattas), both planning authorities and marine industry stakeholders have noted that the sector is not well-characterized with respect to its spatial footprint and an understanding of its component pieces.

Marine recreational use information gaps are a reflection of several factors. One major factor stems from the relationship between regulations and data. In general, industries with more regulatory requirements tend to generate more associated data as a result. For example, mandatory reporting in the commercial fishing and shipping industries leads to more comprehensive data showing the spatial footprint of these activities (ERG 2010). By contrast, the recreational sector has relatively few state or federal regulatory requirements, thereby generating fewer datasets characterizing the activities of that sector. On a related note, the diffuse nature of marine recreational user groups, particularly considering relatively widespread activities (e.g., beach-going, wildlife viewing) makes it challenging to define a distinct subset of the population from which to sample spatial and economic data. This lack of a defined user group is another contributing factor for the historic dearth of marine social sciences studies noted in the NOAA Social Science Working Group's 2009 report to the NOAA Science Advisory Board (NOAA 2009). This report also identified lack of institutional funding, expertise, and motivation as additional reasons for this lack of data.

State and regional marine planning processes in the Northeastern U.S. have begun to effectively address marine recreational data gaps and involve these industries in the process through initiatives that are now either completed or underway. At the state level, both Massachusetts and Rhode Island have engaged and characterized marine industries for both the Massachusetts Ocean Management Plan (2009, 2015), and the Rhode Island Ocean Special Area Management Plan (OSAMP; CRMC 2010, pending 2016 update). At the regional level and in response to establishment of a national marine spatial planning framework (CEQ 2010), the Northeast Regional Planning Body is completing nearly two years of baseline characterization and stakeholder engagement to support the first regional U.S. marine spatial plan, scheduled for completion in late 2016. These efforts have contributed to an expanded understanding of marine recreational uses in the Northeast and advances in use characterization and engagement approaches.

A key component of these efforts is the constructive engagement of various kinds of recreation stakeholders in the marine planning process. For the purpose of discussion within this paper, we define three categories of stakeholders, outlined below, recognizing that there may be overlap among them.

Industry leaders: Individuals whose livelihoods depend on a particular recreational activity. These are typically business owners and/or members of trade associations.

Industry experts: Individuals who have a degree of industry knowledge that extends beyond a casual 
participant in an activity. These include leaders and members of recreational clubs (e.g., diving groups), event organizers, or members of an organization whose work is related to an industry (e.g., non-profit research organizations partnering with whale watch vessels).

Individual participants: Individuals who engage in a recreational activity, but are not likely to be part of an organized entity representing that activity. Their interest in an activity is likely to reflect their personal enjoyment of that activity as an individual, rather than any economic benefits derived; however, their participation in an activity often contributes economic benefits to industry leaders.

Effective communication and outreach approaches to these stakeholders are critical to ensure that data used for planning accurately characterize each industry and, importantly, is trusted by these industries. Collecting accurate, adequate, and trusted data serves several purposes: industry business planning, marine planning, management decision-making, and industry engagement.

\section{PURPOSE AND APPROACH}

For nearly a decade, SeaPlan has supported state and regional planning processes by collaborating on a number of marine human use characterization studies. Our role in these studies, including stakeholder engagement and outreach study design and execution, geospatial analysis, reporting and communicating results, and project management, has positioned SeaPlan at the intersection of industry and government partnerships. This lends SeaPlan a unique vantage point from which to draw insights on human use characterization initiatives and offer these observations to inform future marine planning efforts.

This paper offers a framework for effective approaches to collaborative marine human use characterization, explores associated best practices and strategies, and examines the development and application of these through four case studies. The best practices and lessons distilled from these experiences can be applied not only to future marine recreation studies, but also to any industry that could benefit from more detailed characterization for marine planning purposes. The paper is organized into three sections:

\section{A Collaborative Data Collection and Engagement} Model and Key Strategies

In this section we describe an approach and set of methodological best practices for engagement and data gathering that were employed successfully in the four marine use characterization cases, along with two key strategies used to bolster the success of project outcomes.

\section{Marine Recreational Use Characterization Case Studies}

For each of the four cases we present an overview of the work completed and the entities who executed or contributed to the work. We then offer reflections on how best practices and strategies were manifest and other information that would be useful to fellow practitioners, including lessons learned.

\section{Discussion}

We conclude by distilling three overarching lessons learned that emerge from examining the body of work as a whole. This is followed by a brief summary of how these four case studies addressed the collaborative data and engagement best practices and strategies, informed subsequent methodological refinement, and how use of the model resulted in positive outcomes. We also reflect on how the outcomes from this body of work can inform and positively influence potential future efforts in the region and can be applied to other geographies.

\section{A COLLABORATIVE DATA \\ COLLECTION AND ENGAGEMENT MODEL AND KEY STRATEGIES}

The need for trusted data that meets the needs of planning authorities, regulatory agencies, marine industries, and associated stakeholders drives the collaborative data collection and engagement model ("the model") and its associated strategies. The model's most salient feature is that it explicitly invites input from diverse parties throughout the project, ensuring that the products and outcomes can fulfill multiple objectives. The model's framework emerges from applying principles from previously published work on effective engagement and data gathering techniques (e.g., Pomeroy and 


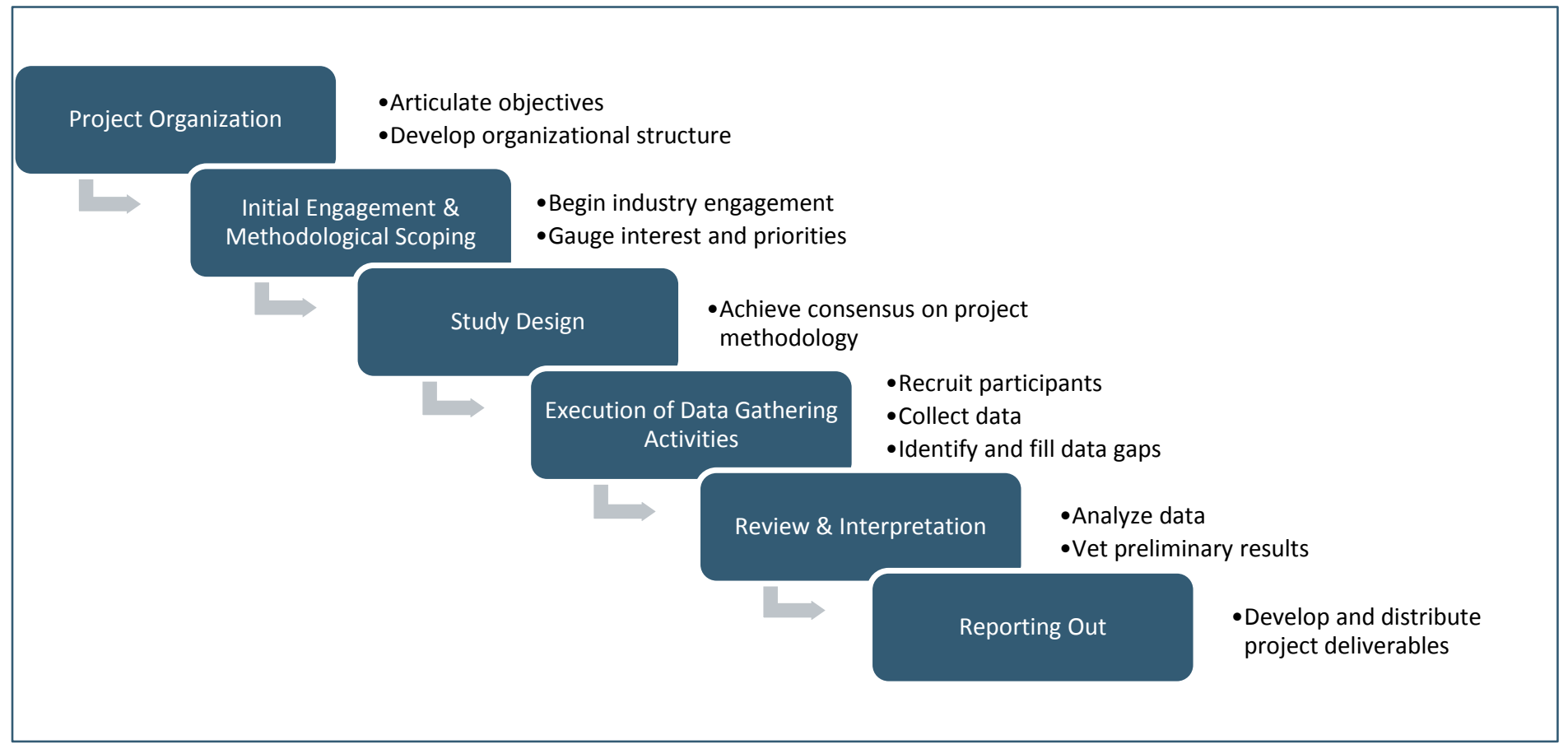

Figure 1. Phases and associated tasks of the collaborative data collection and engagement model

Douvere 2008) to human use characterization in a marine planning context.

\section{THE COLLABORATIVE DATA COLLECTION}

\section{AND ENGAGEMENT MODEL}

The four marine use characterization efforts highlighted in this paper have successfully applied the model. The benefits of the model's approach, the adaptive nature of the model in response to unique industry characteristics, and the specific reflections on the model's application are highlighted below and in Section III - Case Studies, accordingly. We posit that utilizing this model of engagement and data gathering efforts to support marine spatial planning processes has shared benefits for industry members, planners, and managers. The model consists of six phases, found in Figure 1 and described in further detail below.

\section{PHASE 1: PROJECT ORGANIZATION}

In this phase, project organizers respond to a need for new or improved data by articulating study objectives and creating an organizational structure to address these objectives. Often, a planning process identifies research priorities which point to specific data needs, and project organizers develop study objectives

to address these needs. In order to carry out the study, the various planning, management, and stakeholder entities who will be involved in the project begin coordinating to conceive of an overall organizational structure and to solidify project roles.

The organizational structure typically consists of the following entities, defined as follows:

PROJECT ORGANIZER - Initially identifies the need for the project and articulates its general scope and goals. Government agencies and planning authorities often fill this role. In some cases, the project organizer assumes the role of the project manager; in other cases, a project organizer may engage and oversee a project team to conduct the work, sometimes providing resources following a request for proposals (RFP) and a resulting contract.

PROJECT TEAM - A group of entities responsible for carrying out the various, day-to-day components of a project and ensuring that the project moves forward and meets established milestones. Typically, a team consists of a project manager-who often performs additional roles such as stakeholder outreach, data analysis, and reporting - and other consultants or contractors hired to 
provide professional services (e.g., economic analysis, software development). To conduct the work, some members of the project team may be contracted by the project organizer, while others may provide services as part of their organizational mission.

PROJECT ADVISORS - A diverse group of entities or individuals who provide guidance and oversight in various phases of the project. The affiliations and roles of project advisors vary according to the specific needs of the study. They may be involved formally, as in a technical working group or steering committee, or informally, providing periodic guidance and input on an as-needed basis. To ensure that the study's outcomes successfully meet multiple objectives, both government and industry participate in advisory structures:

Government - Government advisors represent the interests of both planning authorities and management agencies. Marine planning generally seeks to understand and characterize a wide range of human uses and marine resource conditions for the purposes of developing sustainable development plans. Marine management is carried out through specific governmental authorities and mandates by individual government entities that require specific data and information relative to these authorities. Planning and management authorities may be distinct entities or may overlap in membership; therefore, some individuals may approach the advisory role from the perspective of both a manager and a planner.

Industry - Industry advisors are typically either recognized industry leaders or industry experts. These individuals often represent established industry organizations, such as trade or business associations, or other organizations that advocate for or work closely with the sector (e.g., clubs, non-profit groups). They may also be individual business owners, club members, event organizers, or anyone who otherwise has an active interest in, and extensive knowledge of, the activity being characterized. Occasionally, advisors may also be particularly enthusiastic individual participants with exceptional knowledge of the industry who are considered able to represent stakeholder interests.

Figure 2 depicts a conceptual schematic of a project team's organizational structure and roles, though the example illustrated here is not fixed. The case studies

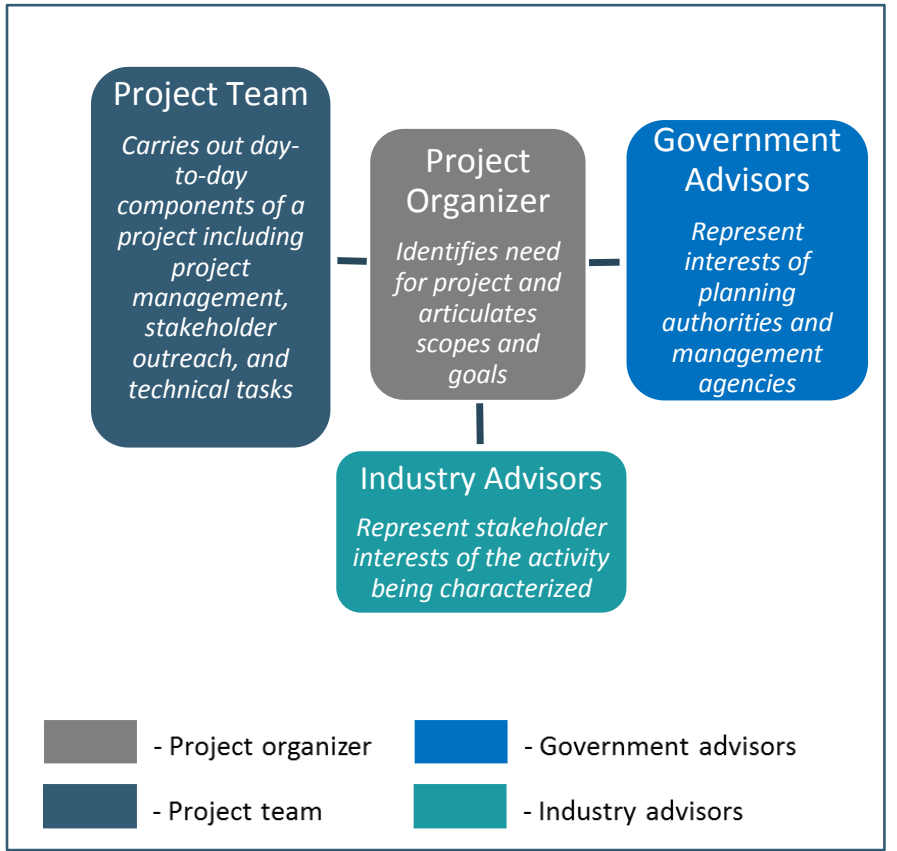

Figure 2. Conceptual model of organizational structure and roles

presented later show how these structures and roles can differ depending on factors such as project objectives and collaborators' respective resources.

\section{PHASE 2: INITIAL ENGAGEMENT AND METHODOLOGICAL SCOPING}

With basic project structures and functions established, the project team can initiate open-ended dialogue with industry experts and advisors to inform three major components of study design. Asking questions corresponding to each component helps to tailor the study to specific industry characteristics. The components and example questions are as follows:

1. Outreach and engagement methods to identify effective avenues for industry involvement throughout project. How is your sector organized and represented in the area? What forms of communication are most effective with your sector? What venues offer the best opportunities to meet with your industry?

2. Data collection and survey design methods to ensure industry participation and data utility. With what type of survey methodology is your industry most likely to engage (i.e., online vs. in-person data collection), and where might there be obstacles to participation? What available existing data can be used to spatially describe your industry and to value it through quantitative or qualitative approaches? Where are 
opportunities to address data gaps or data inaccuracies within your industry? What is the potential utility of data outputs to your sector and what output formats would be most useful?

3. Interest in collaboration to underpin study credibility. Are you interested in collaborating as part of a defined process? Can you recommend other individuals or entities that should be part of this effort? Where are opportunities to ground-truth data once it has been collected?

The discussions during this phase are critical for grounding the project in a pragmatic understanding of industry needs in the context of a marine planning process, and for defining a process to move forward with industry collaboration. This exploratory scoping phase also enables the project team to identify preliminary study design options, including engagement strategies and data collection methods, for refinement in Phase 3.

\section{PHASE 3: STUDY DESIGN}

Using feedback from Phase 2, the project team identifies preferred methodological options for data collection and engagement, then refines those approaches through iterative discussions with government and industry advisors until there is agreement on a detailed study design. Decision points on several key project elements in this process include data collection tools and techniques, survey questions, data outputs, reporting formats and channels, outreach and data vetting plan, study timing and duration, level of effort and specific expertise required, and available resources. This is also an opportunity to discuss any data sensitivities with industry members and determine how they will be addressed.

Once there is agreement on the study's methodological components, the project team can develop the survey instrument, establish analytical parameters (e.g., appropriate sample size and anticipated statistical outputs), refine outreach strategies and develop materials. These steps are ideally accomplished through periodic review by project advisors to ensure survey tool functionality, appropriateness of survey questions, and effectiveness of outreach material formats and content. The outcome of this phase is a complete study design, including a detailed engagement plan and a functional data collection methodology and instrument.

\section{PHASE 4: EXECUTION OF DATA GATHERING ACTIVITIES}

In this phase, the project team implements the data collection methodology developed in Phase 3. A first step is to execute the component of the outreach strategy for recruiting survey participants. Depending on the nature of the target industry stakeholder group, this often involves distributing recruitment materials through predetermined industry-specific channels (e.g., mailing lists, meetings, social media), or leveraging existing industry partnerships to recruit participants through word of mouth. While this typically occurs at the beginning of the survey, it may be necessary to check in mid-way with industry advisors to determine whether initial survey results are yielding sufficient geographical or sectoral representation. If not, industry advisors can guide the project team on modifying the outreach strategy to optimize participation.

The other significant aspect of this phase is deploying the survey tool. Survey deployment requires considerable project management effort to monitor and analyze participation rates and patterns, identify and address technical issues, conduct interim analyses to vet with advisors, and refine survey implementation approaches accordingly. The project case studies below describe a variety of approaches that were utilized in the Northeast to collect marine recreational data and industry participation.

\section{PHASE 5: REVIEW AND INTERPRETATION}

Once data gathering is completed or near completion and the team has conducted initial data analyses, preliminary data products are shared with project advisors, and, ideally, a wider group of stakeholders for their review and input. Depending on the survey design, data vetting may occur in tandem with Phase 4 during pre-established check-in points in the data gathering process. This vetting seeks to answer the following types of questions:

1. Data Quality: How do these data look to you? Are they accurate?

2. Data Gaps: Are there major gaps in the results? If so, how can they be filled? 
3. Data Concerns: What important caveats or data assumptions need to be articulated in order for these results to be accepted within the industry/stakeholder interest community? Are there important data confidentiality concerns that are necessary to address? If so, how can these be addressed in acceptable ways?

4. Data Utility: How would you use these data for specific industry purposes or to improve governmental management and planning processes?

5. Communicating Results: What are the best ways to visually present or represent the survey results?

\section{PHASE 6: REPORTING OUT}

In this phase, the project team translates the study results into a variety of formats and disseminates that information through pre-defined channels. Study results and reporting may take a variety of forms, and include the following:

- Raw and processed data shared back with industry, project partners, and respective planning authorities

- Maps and other data products made public and disseminated via web-based ocean data portals or other means

- Technical reports published that outline the methodological process and present the results of the characterization efforts

A key element of this phase is that the data, information, and knowledge that are gathered are delivered in usable, retrievable, and available formats. Based on input from established working groups and industry vetting, the project may necessitate establishment of important data disclaimers, caveats, or protected data access agreements. For example, some data collected as part of collaborative efforts may be reported to the public, while other data may have confidentiality considerations that restrict its use to industry and governmental interests for specific purposes.

\section{KEY STRATEGIES FOR MODEL EXECUTION}

Through experience adapting the model for successive projects, two strategies emerge that we posit as essential for successful marine human use characterization: data as a shared asset and tailored engagement approaches. This section briefly describes these concepts and important considerations for their application. Section III--Case Studies explores examples of how these key strategies were reflected in the model.

\section{DATA AS A SHARED ASSET}

This strategy is centered on the idea that a well-designed and executed project can simultaneously meet the needs of a diverse set of interests. Industries need trusted and reliable data to make good business decisions and to engage effectively with government and other ocean users on management and regulatory issues. Governments need this information to make sound management decisions on planning, siting, and mitigating the potential impacts of proposed ocean uses. Stakeholder groups can also use data to advocate for their sector. For example, if stakeholders perceive a conflict between their existing activity area and a proposed ocean use, stakeholders may be able to use the data to influence decision makers by demonstrating the impacts of the competing use. When a project's explicit goal is to develop data that serve a purpose for a variety of interests, the project is more likely to garner widespread support.

To meet the needs of government interests, it is important to understand that the data goals of planning and management agencies are likely to overlap, but not align completely. As such, it is important that planning and management agencies coordinate to avoid studies that are duplicative, as industry members are less likely to participate in data collection efforts that they perceive to be redundant. In the best case scenario, human use characterization efforts will be designed to fulfill both specific management and planning objectives simultaneously by developing robust data, deepening industry participation in marine management/planning processes, and creating significant efficiencies for data users and data collaborators. Successful outcomes will ideally extend beyond these results, and may also include mutually-beneficial data infrastructure (i.e., data portals), stakeholder contacts who will be willing to participate in future efforts, and data gathering and update procedures.

Similarly, industry willingness to participate will depend heavily on whether members recognize a need for the study and whether they can envision themselves using the data or other outputs. Because participation in a data collection effort requires time and resources, industry 
must readily see that the outcomes will be mutuallybeneficial. To accomplish this, it is imperative to understand what is considered "valuable" from an industry perspective. Soliciting industry advice in the study design phase can help ensure that the type of data collected, and the way in which it is presented and distributed, can meet industry needs. In this way, industry has a stake in ensuring that data are accurate and trustworthy, and may value data as a means to improve their business function or to meet other critical industry needs. When industry contributes to data development, it is also more likely that industry members will trust and support management and planning decisions that use those data.

For data to have value and utility to all parties, it may need to be available in multiple formats, or contain varying levels of detail. When the suite of data and information generated is mutually valuable, it can create a bridge between government, industry, and other stakeholders to improve communication and build relationships that can establish productive dialogue. In this sense, data become an asset developed and exchanged by and between industry and governmental entities, facilitating effective participation in a project.

\section{TAILORED ENGAGEMENT APPROACHES}

Although this concept may be self-evident to some, our experience underscores the importance of transcending cookie-cutter engagement methods by developing approaches responsive to the particular industry. Project partners employ this strategy to develop relationships that improve understanding of how the industry works: its organization (e.g., leaders and spokespeople versus rank and file membership), preferred communication vehicles, and particular vernacular. These insights allow for the design of appropriate engagement practices for effective communication and selection of pragmatic survey techniques and tools. Overall, tailored approaches improve industry engagement and participation, and thereby enhance project outcomes.

For example, there are strategic advantages to designing engagement approaches that can be deployed using existing industry channels and communication norms, and/or which engage groups that already exist to represent the industry. In some instances, broader industry representation may be most appropriate to meet the needs of the project, survey, or process. In other instances, it may be most efficient and effective to engage fewer key leaders and experts who meet certain criteria for participation, such as individuals who can reflect the geographic distribution of the sector or have a preexisting working relationship with planners and managers.

Temporal components of sector activity also have implications for where, when, and how outreach and data collection activities should be conducted. Stakeholders and industry representatives might be reluctant to participate in time-consuming data collection activities during times of year when the activity in question is at its peak intensity; alternatively, in some cases it may be difficult to achieve a critical mass of industry representatives during times of year when the activity in question is not occurring.

\section{MARINE RECREATIONAL USE CHARACTERIZATION CASE STUDIES}

The four case studies presented in this section are intended to illustrate how the model and its associated strategies have been applied in practice to characterize marine recreational uses in the Northeastern U.S. Figure 3 provides a summary of each project's basic elements, including the geographic scale, targeted sector(s), technical components, and final products. In the subsequent narrative summaries, we describe how the model was adapted for each project. Rather than describe every phase of each project in detail, we have highlighted aspects of each project that diverged from previous studies or had otherwise unique or notable characteristics. We end each case study by offering key reflections and lessons learned that were used to inform development of subsequent projects and that may be considered in future human use characterization studies. Detailed information regarding the methods, analyses, and results of each of these studies can be readily found in individual study publications and publicly-available websites. 


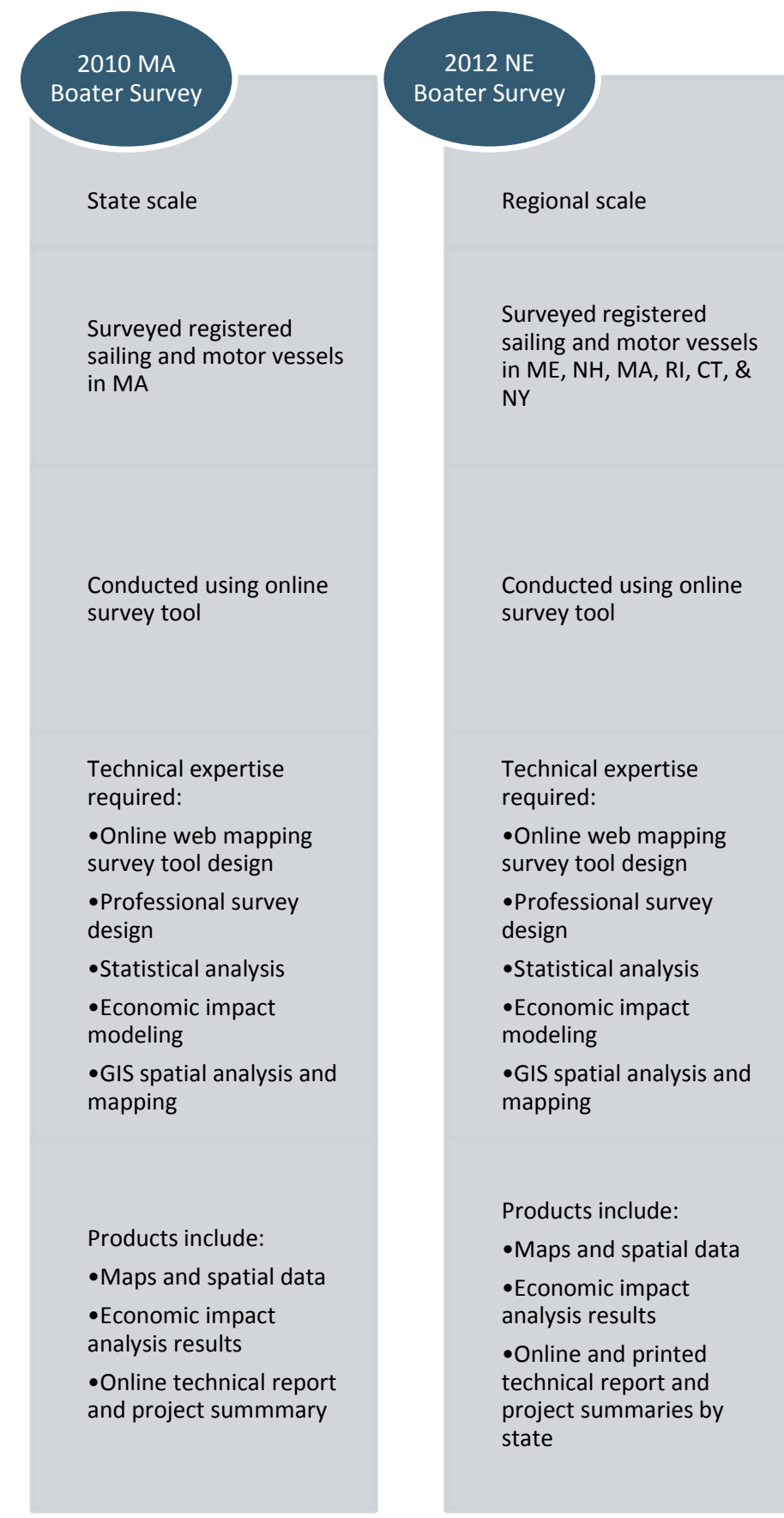

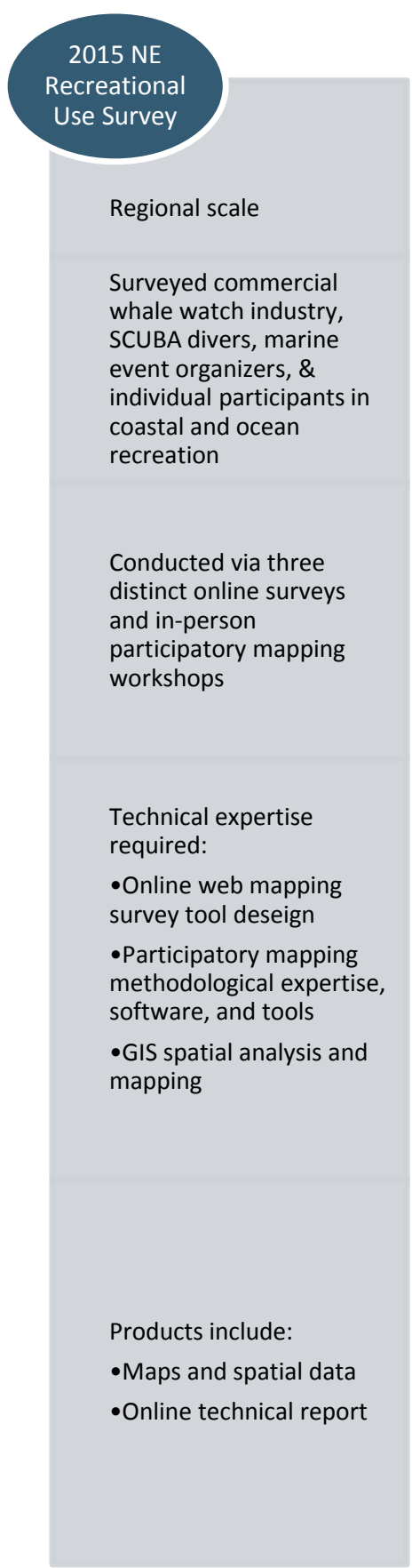

$2013-2016$

Charter \&

Party Vessel

Survey

Sub-regional scale

Surveyed commercial charter and party boat operators in $\mathrm{RI}, \mathrm{CT}$, \& NY

Conducted using tabletbased data collection tool

Technical expertise required:

-Tablet-based application design

-Tablet equipment management

-Database management - GIS spatial analysis and mapping

Products include:

- Maps and spatial data

- Online technical report

-Downloadable tabletbased application

Figure 3. Summary of marine recreational use characterization project case studies 
2010 MASSACHUSETTS RECREATIONAL

\section{BOATER SURVEY}

\section{SUMMARY OF WORK}

The 2010 Massachusetts Recreational Boater Survey (2010 MA Boater Survey) gathered information on recreational boating activity in Massachusetts during the 2010 boating season. The project team invited 10,000 owners of Massachusetts registered and documented vessels to participate. Twenty-two percent of invited boaters responded and provided detailed information about their boating trips, recreational activities, and trip-related expenditures through a series of monthly online surveys using an online mapping tool. An end-of-season survey also captured data on annual capital expenses.

Final study products include maps of recreational boating routes, densities, and activity areas and economic impact analysis results showing that boating trips along roughly 1,100 mapped routes generated more than $\$ 806$ million and supported over 4,730 in-state jobs. For more information, see the project summary and the full

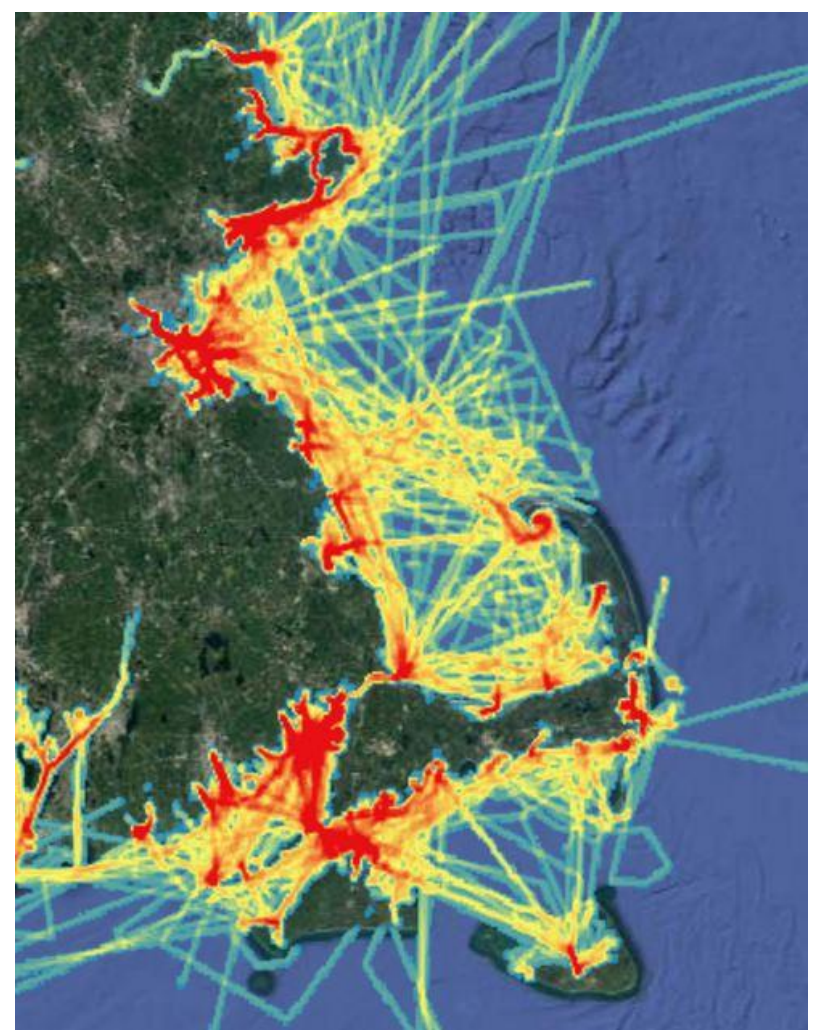

Figure 4. Example result from the 2010 MA Boater Survey on MORIS technical report (Hellin et al. 2011). Figure 4 depicts an example map product from the study. The results of this study have been used to inform state ocean planning efforts, and were updated two years later when the study was replicated and expanded to a regional level in the 2012 Northeast Recreational Boater Survey.

\section{APPLICATION OF THE COLLABORATIVE DATA COLLECTION AND ENGAGEMENT BEST PRACTICE MODEL AND KEY STRATEGIES}

The 2009 Massachusetts Ocean Management Plan identified recreational boating use patterns and economic impact as a priority information gap to be addressed for Plan implementation and updates. In coordination with the Massachusetts Office of Coastal Zone Management (MA CZM), the Massachusetts Ocean Partnership (now SeaPlan) engaged a team of consultants and formed a government-industry advisory committee that laid the groundwork for collaboration in subsequent project phases. The primary industry advisor, the Massachusetts Marine Trades Association, provided significant guidance throughout the study, including input on the type of survey instrument that could reach the greatest number of participants and the particular survey questions to ensure the study was relevant and understandable to Massachusetts boaters. A broader group of industry advisors were instrumental in beta testing the online mapping software and enhancing awareness of the study in the boating community through flyers, presentations, and web-based forums. In later phases of the project, industry advisors helped the project team evaluate the accuracy of the results from an industry perspective, reviewed draft technical report materials, and disseminated results to other industry members.

The team's coordination with boating industry leaders and experts as well as planning and management authorities throughout design and execution allowed the study to produce for the first time spatial, demographic, and economic impact information which had considerable utility to all parties. Figure 5 depicts the organizational structure of the project.

MA CZM was able to address a priority recreation data gap identified in its ocean plan. The Massachusetts 


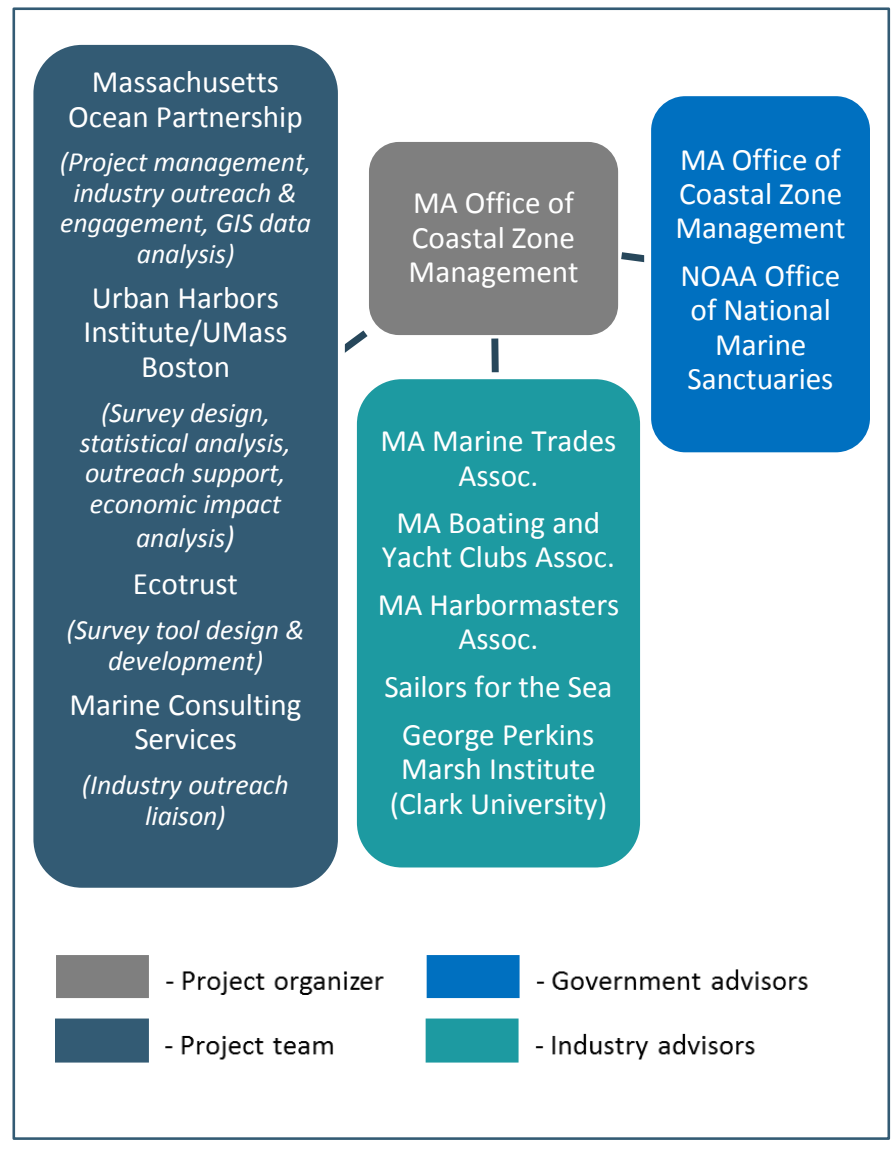

Figure 5. Organizational structure of the 2010 MA Boater Survey

Environmental Police (MEP) and U.S. Coast Guard (USCG), whose registration databases were the source of licensed boater participants, incorporated the analysis in carrying out their responsibilities.

Industry members' willingness to advise throughout and provide survey participation incentives (e.g., gift certificates, merchandise, and cash rewards) demonstrated their investment in, and the value of, generating high quality data products. For boating stakeholders, the value of the study was evident in the results of the end-of-season survey, where participants indicated their hope that the results would be used to highlight the significance of recreational boating in Massachusetts waters and requested that results be made available to the public. The project's timeline and the duration of tasks are depicted in Figure 6.

\section{KEY REFLECTIONS AND LESSONS LEARNED}

Considered the first application of its kind among ocean interests, the 2010 MA Boater Survey established a replicable collaborative methodology that demonstrated success in garnering high participation rates and forging effective partnerships between industry and government. Subsequent studies, described below, were able to leverage the flexibility of the model both to scale the study to a regional level and to adapt the methodology to suit the unique needs of other industry stakeholder groups. The role of industry partners in tailoring engagement approaches, establishing trust in survey methodologies and results, and encouraging participation is considered to be a driving force of this study's success.

This application of the collaborative model also highlighted a key lesson: engaging industry advisors in a thorough survey design process and in subsequent outreach efforts requires a great deal of time and coordination. While the project was considered a success, the project team concluded that it could have been

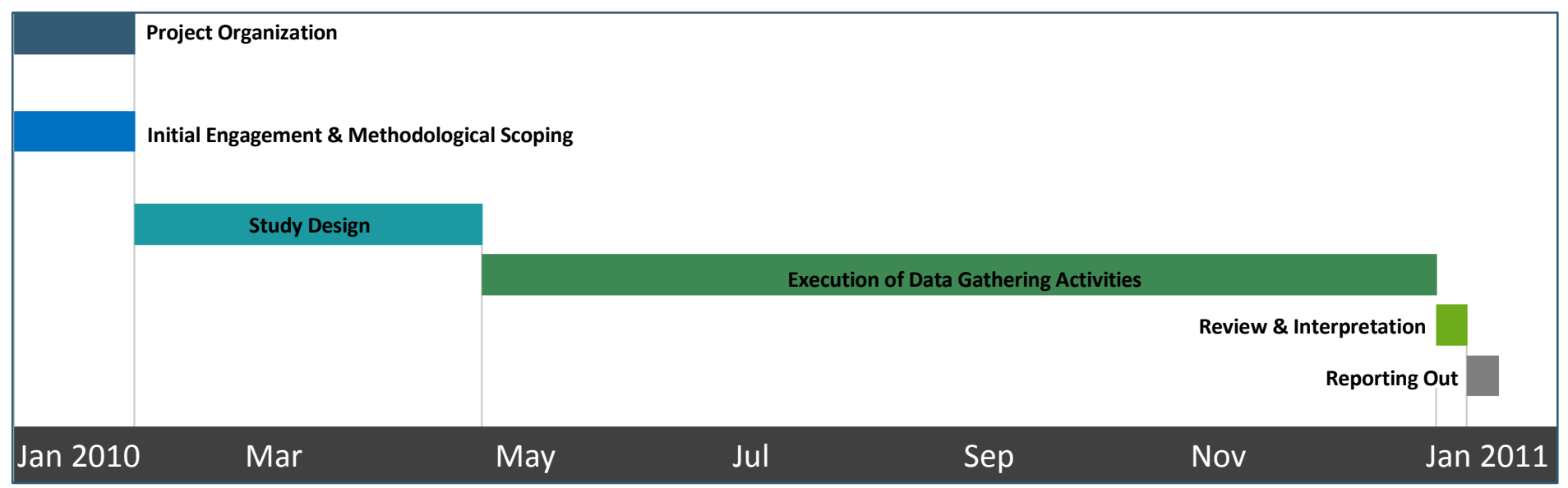

Figure 6. Timeline and duration for the 2010 MA Boater Survey 


\section{HIGHLIGHTED OUTCOMES OF THE 2010 MA BOATER SURVEY}

- Methodology was used as a model for

subsequent regional boater surveys, confirming

utility of online survey tool.

- Study enhanced stakeholder participation in

state planning efforts and garnered high

participation, confirming the online survey

tool's utility and enthusiasm for participation in

future studies.

- Data were added to the Massachusetts Ocean

Resource Information System (MORIS) ${ }^{1}$ and

included in the update of the 2015

Massachusetts Ocean Management Plan.

1. http://maps.massgis.state.ma.us/map_ol/moris.php

improved if the project's timeline hadn't been compressed into a single year. Specifically, the study would have benefited from more time spent on survey design; boater outreach; and developing, testing, and refining the mapping application.

\section{NORTHEAST RECREATIONAL BOATER} SURVEY

\section{SUMMARY OF WORK}

Building off of the success and adapting the methodology of the 2010 MA Boater Survey, the 2012 Northeast Recreational Boater Survey (2012 NE Boater Survey) targeted marine recreational boaters from Maine, New Hampshire, Massachusetts, Rhode Island, Connecticut, and New York during the 2012 boating season. To characterize the 373,766 registered boats from coastal counties in the study area, the project team invited approximately 68,000 randomly selected boat owners. Ultimately, over 12,000 boat owners (18.5\%) participated in the survey. Using an online tool, participants mapped their boating trips and activities and reported their trip- related expenditures on a monthly basis. In an end-ofseason survey, participants provided information about annual boating expenditures and, through a newly introduced component, shared their opinions on marine issues, such as boating safety and compatibility with other ocean uses, including offshore wind farms, ports, aquaculture, and marine protected areas.

Final study results include region-wide and state-specific maps of recreational boating routes and activity areas and economic impact analysis results showing that 907,000 ocean boating trips generated approximately $\$ 3.5$ billion and the equivalent of nearly 27,000 year-round jobs in the Northeast in 2012. For more information, see the Marine Recreational Boating website for links to the overall project summary, state summaries, full technical report (Starbuck and Lipsky 2013), and links to data and maps. Figure 7 depicts an example map product from the study. The results of the study have been used to inform regional ocean planning efforts by identifying waters important to the sector and better understanding views about compatibility with other uses. The information may continue to be used by resource managers planning for sustainable ocean uses and boating safety, and by the boating industry for strategic business planning.

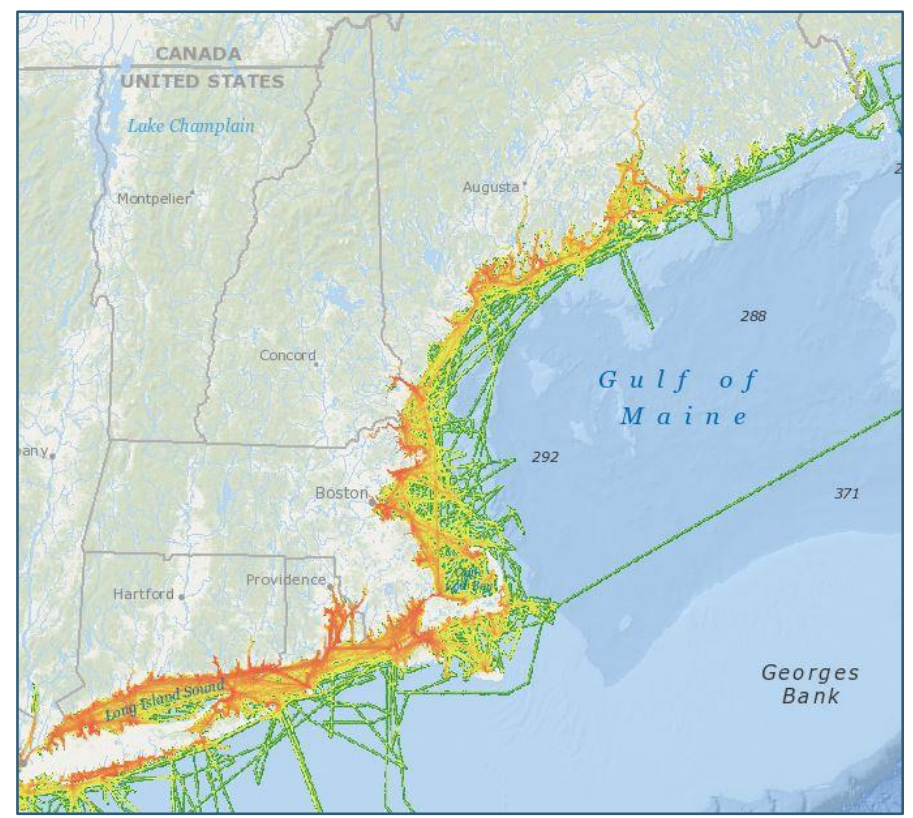

Figure 7. Example result from the 2012 NE Boater Survey on the Northeast Ocean Data Portal 


\section{APPLICATION OF THE COLLABORATIVE DATA COLLECTION AND ENGAGEMENT BEST PRACTICE MODEL AND KEY STRATEGIES}

Building on the success and lessons of the Massachusetts effort, regional ocean planning authorities proactively identified a need for reliable region-wide information on recreational boating to inform their ocean planning process. While the primary components of the study's structure, including engagement and recruitment approaches and survey instrument design, mirrored the 2010 MA Boater Survey, the project team and advisors had to adapt the model to address key challenges associated with effectively scaling the effort to a much larger application.

To scale and tailor the outreach approaches, boating industry advisors provided essential perspective in developing and implementing state-specific and regionwide engagement strategies that reflected organizational nuances across the multi-state recreational boating community and comprehensively targeted a wide variety of channels across the region. Working with industry advisors, the project team spread the word about the survey through specific and specialized boating channels (e.g., newsletters) and common recreational boating fora (e.g., boat shows). To help create "buzz" in the boater community and sustain participation, the team developed a project webpage that allowed participants and advisors to easily find study updates and share their stories. Another strategy involved industry collaborators (e.g., marinas, boating associations, marine trades associations) across the region co-hosting meetings to

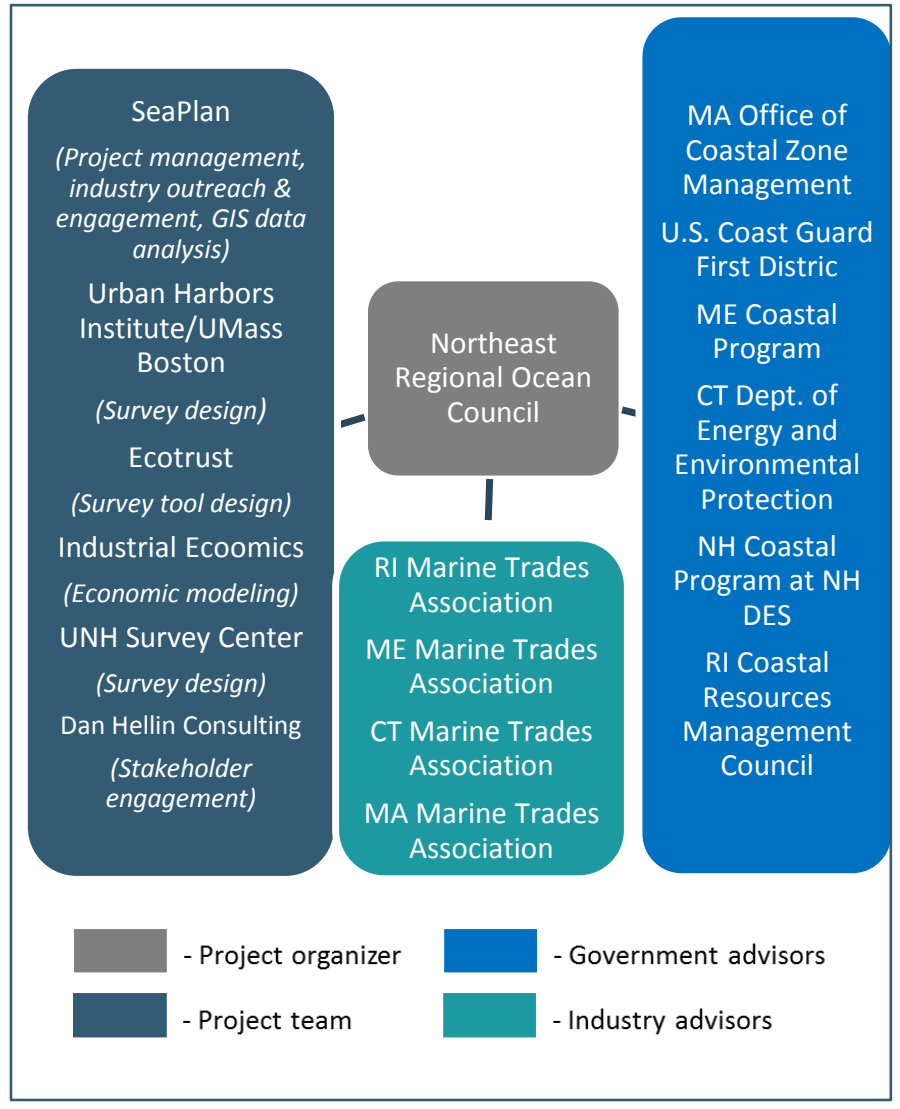

Figure 8. Organizational structure of the 2012 NE Boater Survey

introduce the project, and later, to vet the data. This tactic helped draw greater attendance thereby enhancing engagement from recreational boating leaders and experts across the region to participate in the ocean planning process. Figure 8 depicts the organizational structure of the project.

Project Organization

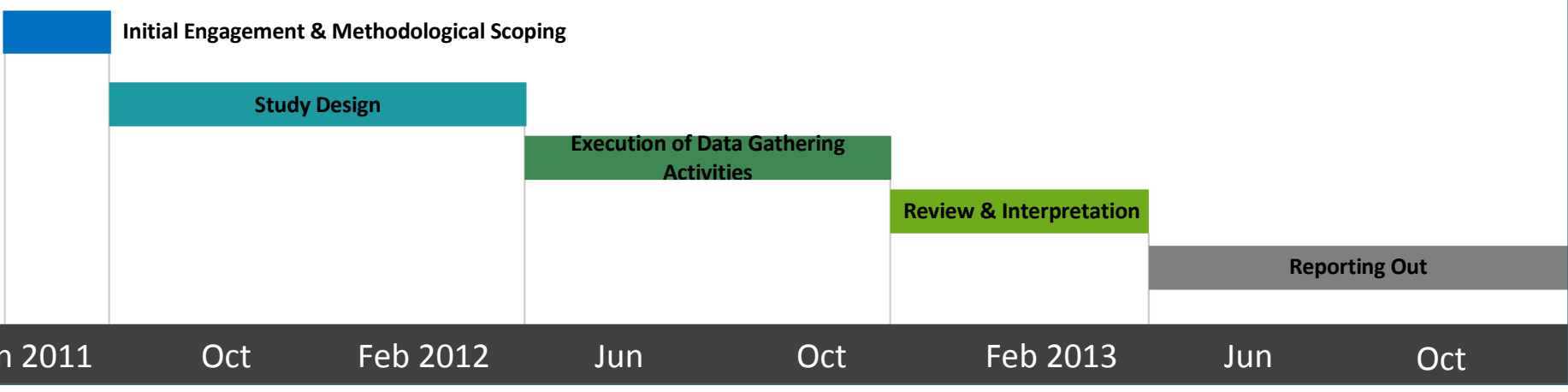

Figure 9. Timeline and duration for the $\mathbf{2 0 1 2}$ NE Boater Survey 
Scaling participant recruitment to the regional level posed significant technical and project resource challenges, particularly when it came to contending with state-by-state differences in the organization of and access to boater registration data. Addressing these challenges was critical, because the utility and credibility of the study results were dependent, in part, on recruiting a representative sample of boaters from each state. State agency advisors played a key role in addressing these obstacles. Similar to the Massachusetts study, shared government and industry interest in filling socioeconomic and spatial data gaps drove the project's study design and overall momentum. While all parties recognized the shared utility of boater opinion, spatial, and economic data, certain aspects of the study design responded specifically to government or industry needs. To satisfy many planning and management objectives, the 2012 study incorporated a new component as part of the year-end survey to gather boaters' opinions on key issues (e.g., compatibility with other uses, safety). One state even provided supplemental financial resources to sample an additional 10, 000 boats for its own planning and management analysis. The industry, and the marine trades associations in particular, wanted reliable recreational boating data to help ensure that agencies adequately account for the sector's contributions to local economies and understand how the boater stakeholder community as a whole uses the marine space, which led to high resolution spatial and economic information data collection elements in the study. To that end, industry willingness to donate products and services to incentivize participation in the survey demonstrated their investment in quality data outcomes. The project's timeline and the duration of tasks are depicted in Figure 9.

\section{KEY REFLECTIONS AND LESSONS LEARNED}

This project demonstrated that the methodology established in the Massachusetts study was scalable, and that industry enthusiasm for data representing their sector extended to regional level. A key highlight from this project was the high level of sustained engagement by industry partners, which contributed to the development of data that the industry has since viewed positively.

Many of the lessons learned during this project stem from the challenges of scaling a project methodology from a

\section{HIGHLIGHTED OUTCOMES OF THE 2012 NE BOATER SURVEY}

- The high survey response rate $(18.5 \%)$ was attributed to industry collaborators and industry partners' assistance in outreach efforts, leading to an increase in the power of the survey.

- Industry co-hosting of data vetting meetings generated significant social capital between industry representatives and the many governmental entities that were part of the collaborative process.

- Government authorities view the resulting survey data as vital information that improves their capacity to carry out their respective planning and management responsibilities.

- Recreational boating interests now have trusted data to advocate for their sector.

- The survey data have proven useful to inform joint government-to-industry discussions and to make smarter decisions about potential interactions between emerging uses, such as offshore wind energy, with longstanding recreational boating uses.

- Data were added to the Northeast Ocean Data Portal $^{1}$ and will be included in the Northeast Regional Ocean Plan. ${ }^{2}$

1. http://northeastoceandata.org

2. http://neoceanplanning.org/plan/

state-to-regional scale. For example, navigating and addressing differences in boater registration regulations and database content and accessibility required time and resources beyond what was necessary for the Massachusetts survey, and relied on partnerships with state regulatory and management bodies. This project report also recommended investigating whether individual states have additional existing sources of authoritative and related data that could be useful in 
ground-truthing data or filling known data gaps. For example, the Massachusetts Marine Trades Association conducted a 2013 survey which, despite using a different methodology, was useful in identifying potential gaps in the study's data. This study suggested that like Massachusetts, other states may have other sources of fine-scale data that could be used to analyze the results of this and other regional data collection efforts.

Finally, this study highlighted the need for more comprehensive data on other recreational activities that often occur in association with or in close physical proximity to recreational boating. For example, while this study collected data points depicting the locations where boaters went swimming, fishing, SCUBA diving, wildlife viewing, or were generally relaxing during their trip, the resulting data are not considered representative of all individuals participating in these activities. Similarly, because this survey sampled from registered vessels, it did not capture the activity of kayaks or other paddlebased boats. It also excluded charter and other "for-hire" vessels. Boaters also pointed out that by not accounting for races and regattas, the data do not reflect the bursts of boating and economic activity that take place surrounding these events. These and other caveats that emerged from the study highlighted the need to characterize a broader spectrum of recreational activities during future studies.

\section{NORTHEAST COASTAL AND MARINE RECREATIONAL USE CHARACTERIZATION SURVEY}

\section{SUMMARY OF WORK}

The 2015 Northeast Coastal and Marine Recreational Use Characterization Survey (2015 NE Recreational Use Survey) characterized a wide array of recreational activities in the coastal and ocean waters of the Northeastern U.S. Industry advisors guided the design of surveys intended to gather input from a wider pool of industry leaders and experts. Two of these industryfocused surveys used web-based survey tools to collect data on SCUBA diving and marine events (sailing races and regattas, sport fishing tournaments, and competitive board and paddle events), respectively. Another industry-focused survey consisted of a series of in-person participatory mapping workshops with whale watching industry leaders and experts. Additionally, a web-based

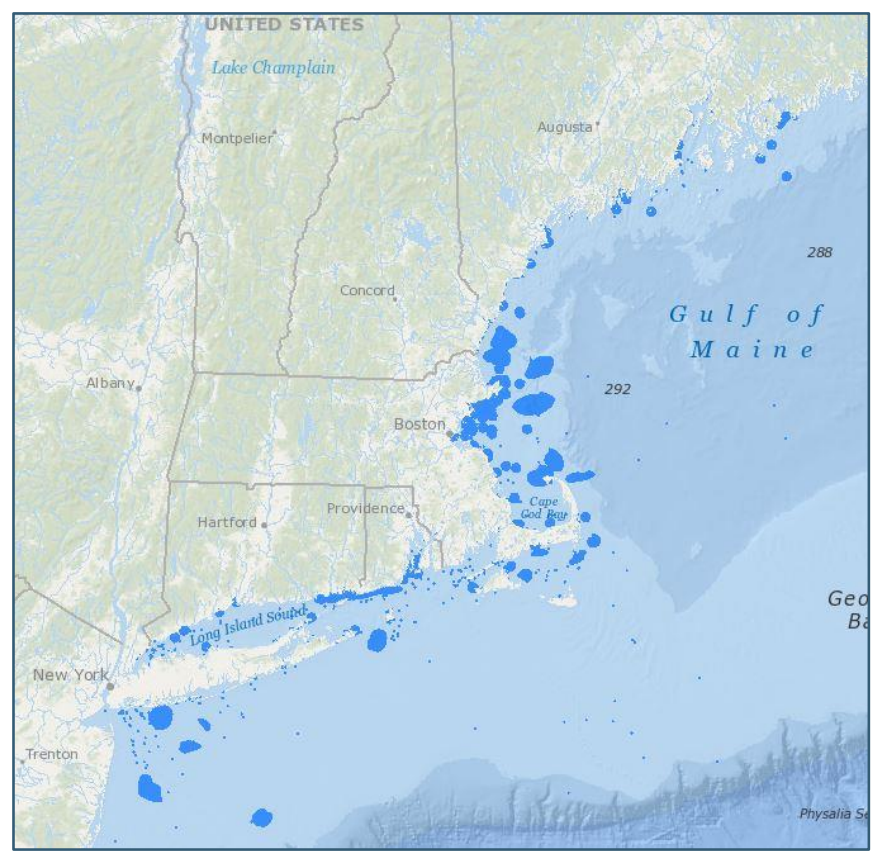

Figure 10. Example result from the 2015 NE Recreational Use Survey on the Northeast Ocean Data Portal

individual user survey was designed to target individual participants in coastal and ocean recreational activities from the general population, and collected information on activities such as beach-going, wildlife viewing, surfing, and non-motorized boating.

Final study results for the specific recreational sub-sectors include region-wide maps of general and site-specific SCUBA diving use areas, general and dominant whale watching use areas, and cruising routes of distance sailing race events. Figure 10 depicts an example map product from the study. Data for regional sailing races and regattas, saltwater sport fishing tournaments, and competitive board and paddle events were reported in tabular format and in maps of the events' landside locations. These data were based on a combination of survey responses and background research conducted by the study team. For more information on the study, see the full technical report (Bloeser et al. 2015). The results of this study have been used to inform regional ocean planning efforts by identifying waters important to popular recreational activities, and have helped build awareness of marine planning efforts among recreational users, groups, and associations. 

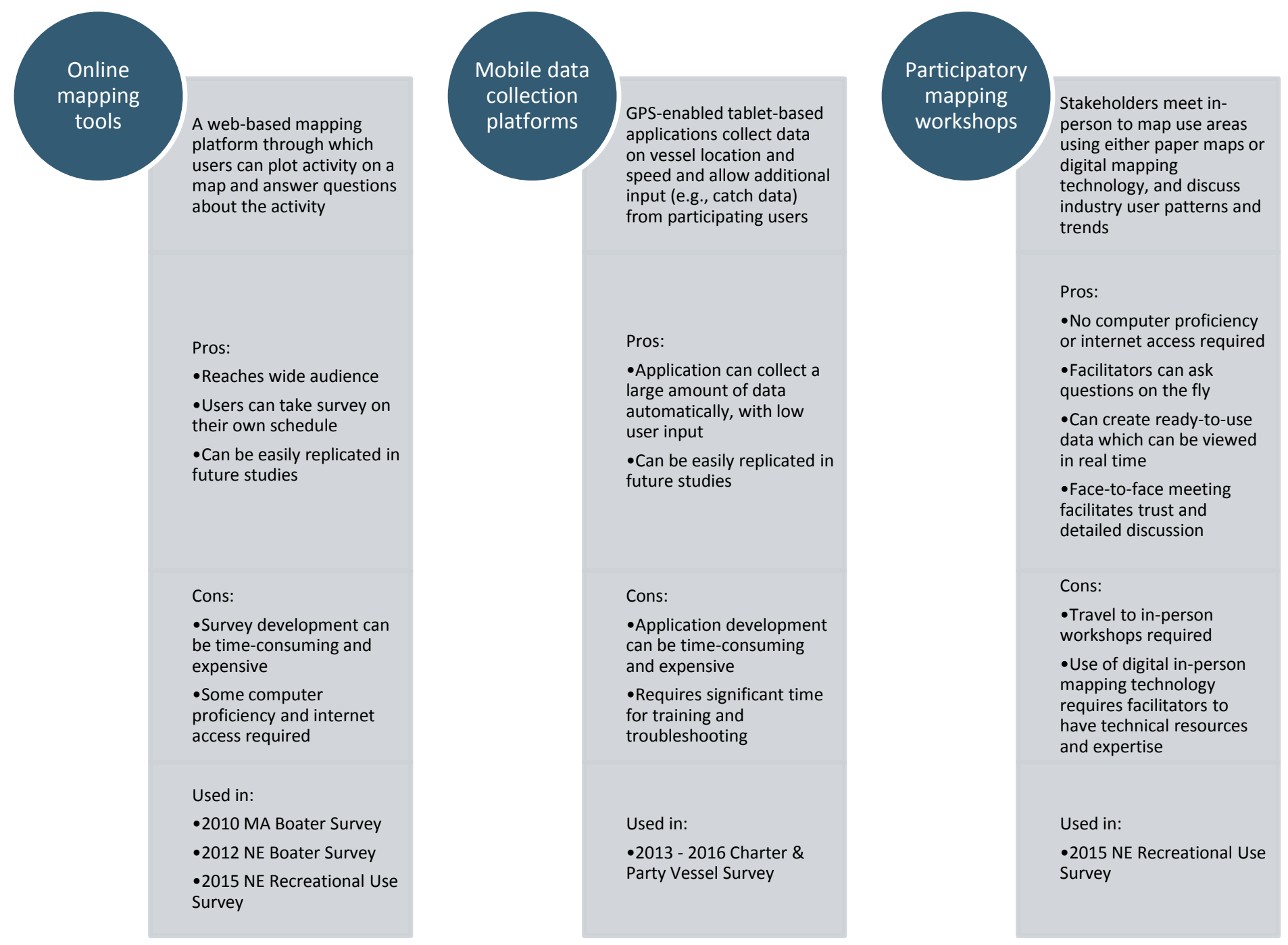

Figure 11. Comparison of data collection methodologies used in recreational use characterization studies

\section{APPLICATION OF THE COLLABORATIVE DATA COLLECTION AND ENGAGEMENT BEST PRACTICE MODEL AND KEY STRATEGIES}

This project diverged from the two recreational boating studies described above, in that instead of targeting a single stakeholder group, it collected data from a broad, diverse group of industries and individual stakeholders from across several coastal and marine recreation subsectors. This study was essentially a set of several methodologically-distinct sub-studies, bundled into one overarching project with common goals, objectives, and timeframe. This necessitated an approach which employed a variety of methodological data collection tools, each tailored to its target industry or stakeholder group. In the early stages of the project, the project team held kick-off meetings with specific industry groups (e.g., SCUBA, whale watching). Industry leaders and experts were presented with a list of potential survey methodologies along with their pros and cons (see a summary of options in Figure 11). Consensus among these industry advisors informed which methodological approach would be developed for the project, and offered additional input as to how the characteristics of each industry group could inform preferred methods for the data vetting and review phase of the project.

While some of the methodologies chosen by industry advisors were similar to those employed in previous studies (i.e., online survey tools), other industry groups stated a preference for in-person data collection 
techniques that required a separate set of technologies and methodological considerations. The project team leveraged its collaboration with the National Oceanic and Atmospheric Administration (NOAA) to deploy participatory geographic information system (GIS) equipment and, with the help of NOAA staffers, adapt the agency's methodology for in-person participatory mapping and data gathering techniques (NOAA 2014) to fit project requirements.

As in previous studies, the project team relied on members of its advisory group, composed of members of the Northeast Regional Planning Body, to help identify key industry stakeholders for the project. Many state managers also had previously-established relationships

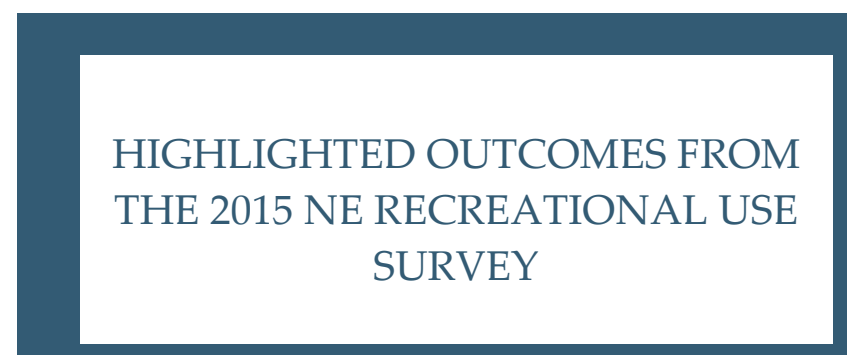

- Tailoring methodologies to specific industries and sub-sectors enhanced industry participation and resulted in previously-unavailable data that has utility for industry business planning, stakeholders, and government agencies alike.

- Positive feedback from the commercial whale watching community indicated that the participatory process utilized for the project brought members of their respective industry together for the first time to discuss industry trends in new and innovative ways and this stimulated new business relationships among industry representatives.

- Data were added to the Northeast Ocean Data Portal ${ }^{1}$ and will be included in the Northeast Regional Ocean Plan. ${ }^{2}$

1. http://northeastoceandata.org

2. http://neoceanplanning.org/plan/

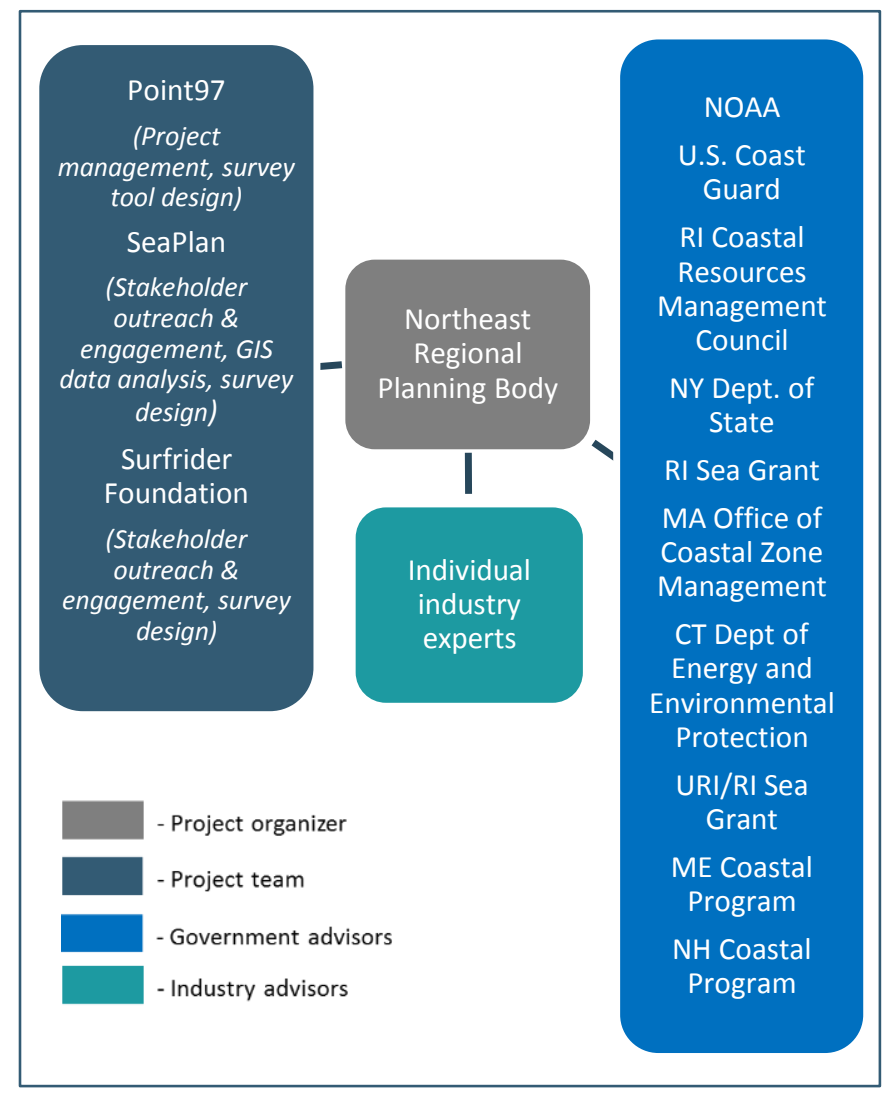

Figure 12. Organizational structure of the 2015 NE Recreational Use Survey

with industry members as a result of prior planning and engagement efforts, and were able to leverage those relationships for this study. In particular, partnership with state management agencies led to a unique opportunity for collaboration as the study's data collection phase coincided with the Rhode Island Coastal Resources Management Council's (RI CRMC) update of the state's OSAMP. The project team attended OSAMP update stakeholder meetings and worked with RI CRMC to collect data that contributed to both the survey and to the state management efforts. There were a number of industry leaders and experts, including SCUBA divers, sailors, and charter captains who were already familiar with and willing to participate in the OSAMP process, which created a more efficient stakeholder engagement and data collection process in this state. Figure 12 depicts the organizational structure of the project, and the project's timeline and the duration of tasks are depicted in Figure 13. 


\section{KEY REFLECTIONS AND LESSONS LEARNED}

This study highlighted the challenge of developing a collaboration among diverse and disparate sectors and government interests, underscoring the fact that there is no "one size fits all" approach to survey tool development, data collection, and outreach. With help from project collaborators representing a broad spectrum of recreational interests, the project team was able to construct approaches tailored to unique industry characteristics. For example, the dispersed nature of SCUBA interests across the region shaped a methodology which relied less on in-person meetings and instead leveraged web technologies as the primary survey instruments. Industry advisors pointed the study team to digital outreach channels such as social media and mailing lists that they could use to encourage participation. Conversely, whale watch industry contacts were more enthusiastic about sharing data at in-person gatherings held near geographic "hubs" of the whale watch industry. Industry representatives provided advice on the time of year when the team could most likely to optimize industry participation, and the data collected during these meetings provided greater geographic coverage compared to the other sub-sector components.

Another way in which industry experts were able to help the team tailor their approach was by helping the team to understand existing sources of data for specific industries and activities, and how limitations of these data sources could be addressed through the study. For example, advisors from the SCUBA sub-sector pointed out that the national dataset on marine wrecks and obstructions does not distinguish between dive sites and other underwater features, and is considered by many to be unreliable when it comes to identifying the locations of certain wrecks. By proposing a way of collecting more accurate data based on industry knowledge, we were able to emphasize the value of study outcomes to industry partners, so that they could champion the concept of data as a shared asset and encourage participation within their industry.

Finally, a major lesson learned over the course of this study is the benefit of using the data review period to collect additional data and fill data gaps. At in-person data review meetings with SCUBA industry members, the project team repurposed the participatory mapping technology used in the whale watch data collection methodology to allow participants to add or edit data on the fly. This process allowed the team to gather additional information even after the online survey tool data collection period had closed. This also enhanced dialogue between SCUBA stakeholders and the project team, resulting in industry members' providing feedback that could be used in future studies. For example, although the project team had a presence at two significant regional SCUBA conferences, divers suggested that the team could have put additional resources into publicizing the study at these events. Future projects might consider identifying important industry events, utilizing project resources to have a presence at these events, and adapting project timelines to accommodate these events, where possible. 
2013-2016 PILOT CHARTER AND PARTY VESSEL FISHING MAPPING PROJECT

\section{SUMMARY OF WORK}

The 2013-2016 Pilot Charter and Party Vessel Fishing Mapping Survey (2013 - 2016 Charter and Party Vessel Survey) collected information regarding party and charter vessel activity from Rhode Island during the 20132014 recreational fishing season, and from Rhode Island, Connecticut, and New York during the 2015 season. The purpose of this human use characterization study was to test technologies and approaches to working with industry to advance electronic reporting and mapping areas important to party and charter boat fishing interests.

This project built upon an existing pilot study initiated by the Rhode Island Party and Charter Boat Association (RIPCBA) that collected catch data and mapped charter boat activity in Rhode Island using a mobile tablet application. In 2014, the Northeast Regional Ocean Council (NROC) and SeaPlan partnered with RIPCBA and software developers to modify the mobile application into a Standard Atlantic Fisheries Information System (SAFIS) Electronic Trip Reporting mobile platform (SAFIS eTRIPS Mobile), which allowed catch and effort reporting and location tracking. In 2015, project partners expanded the pilot study to the Northeast region, recruiting 14 captains from Rhode Island, Connecticut, and New York as participants. Captains were outfitted with mobile tablets operating SAFIS eTRIPS Mobile, which participants used throughout the season to record trip location, effort, and catch information. During the fall and winter of 2015 and early

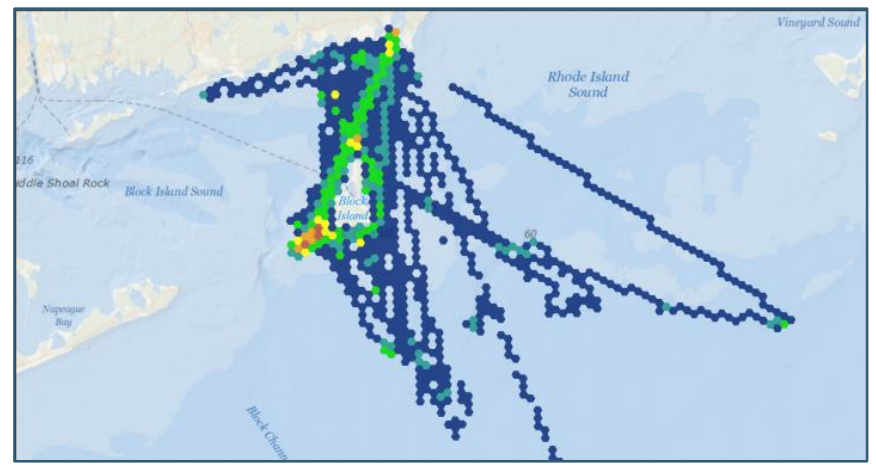

Figure 14. Example result from the 2013-2016 Charter and Party Vessel Survey found in the project report
2016, project partners met with participating captains to vet data collected and gather feedback on the program.

The SAFIS eTRIPS Mobile application collected data in two ways: 1) directly entered into tablets by captains, and 2) automatically from tablet GPS data. Data were transmitted to the Atlantic Coastal Cooperative Statistics Program (ACCSP), who processed and delivered the data to state managers to satisfy state reporting requirements. The pilot study results include maps of party and charter vessel activity for a total of 167 fishing trips in Rhode Island, Connecticut, and New York. Figure 14 depicts an example map product from the study. For more information, see the Pilot Party and Charter Vessel Mapping Study report (SeaPlan 2016). Following completion of the pilot study in 2015, partners are working to moderately expand the program to more participants in 2016 with the intent of laying a foundation for a potential large-scale, region-wide effort in the future.

\section{APPLICATION OF THE COLLABORATIVE DATA COLLECTION AND ENGAGEMENT BEST PRACTICE MODEL AND KEY STRATEGIES}

A key distinction between this case and the others is that the effort was originally initiated by industry, through the work of RICPBA, and governmental participation was invited (e.g., NROC) to form a government-industry collaboration. The project team worked through the industry partnership to leverage industry association meetings (e.g., RIPCBA and the Connecticut Charter and Party Boat Association) as an outreach vehicle for potentially interested captains. This face-to-face strategy helped establish relationships between the team and prospective participating captains, which were needed to build sufficient trust that sensitive geographic information shared would be treated appropriately. Figure 15 depicts the organizational structure of the project.

This project is also unique among these case studies in the degree to which it created an intersection between specific resource management and broader ocean planning needs. Because mandatory reporting regulations are already in place for this industry, this project required greater involvement by other governmental stakeholders previously uninvolved in 


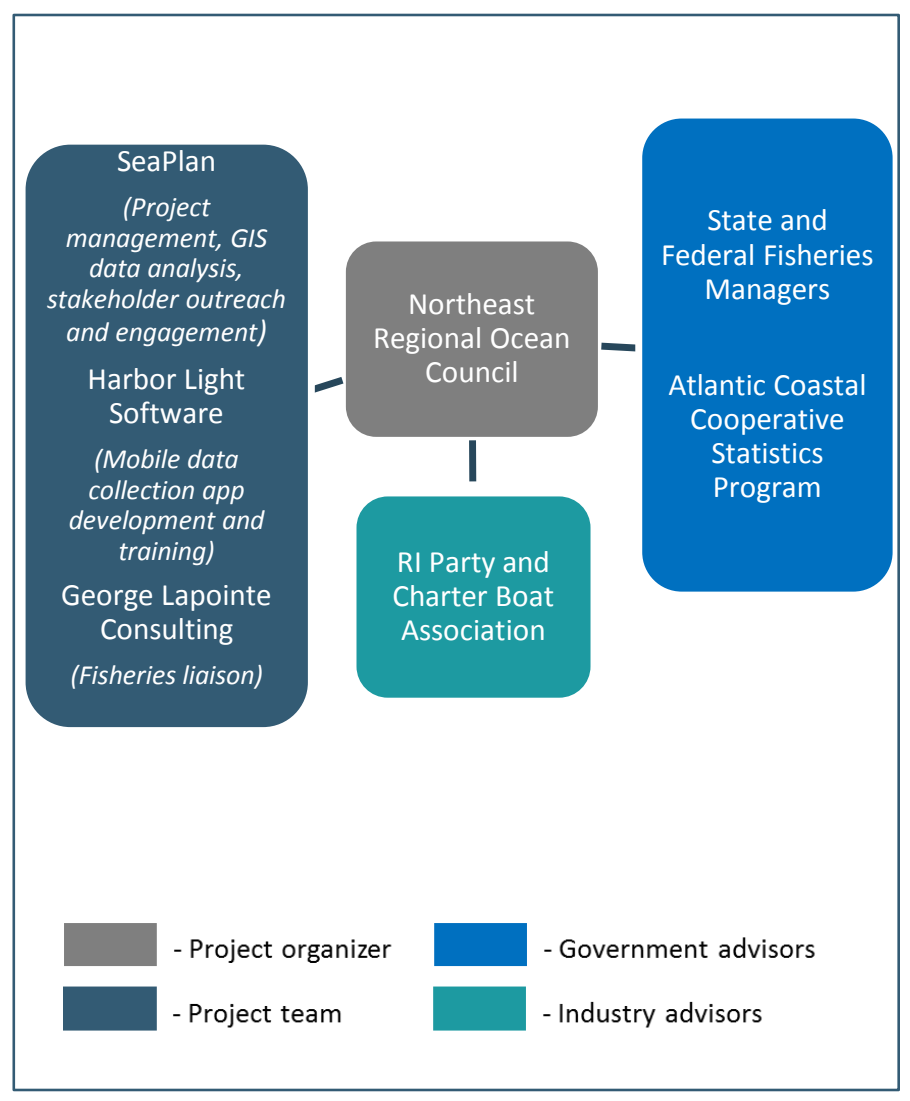

Figure 15. Organizational structure of the 2013 - 2016 Charter and Party Vessel Survey

planning efforts (e.g., state and federal fisheries managers) and data providers (e.g., ACCSP) to ensure that the survey instrument was not redundant or in conflict with existing reporting tools and protocols. While this obstacle meant that the project team had to revisit the initial phase of the project to engage a larger coalition of collaborators and deal with complex technical challenges, the resulting data collection application, which employs hand-held mobile tablet technology and software, has been certified by the National Marine Fisheries Service as an approved electronic reporting device, allowing the application to be used as a federal fisheries management tool. This outcome allows the data collected to be used to serve multiple purposes and creates increased efficiency and data utility for industry members. The project's timeline and the duration of tasks are depicted in Figure 16.

\section{KEY REFLECTIONS AND LESSONS LEARNED}

In this project we observed how industry initiative and motivation can sustain a project through the many challenges of aligning industry, planning, and management interests and objectives. It was clear that if the project developed a data collection tool that only worked for planning purposes and that did not also function for management purposes (catch reporting), then the tool would be less useful for industry interests and would hamper industry participation and trust in the project as a whole. The efforts to obtain "buy-in" from appropriate fishery management authorities at the regional and state level resulted in an effective, wellorganized, and better-supported pilot initiative.

One major takeaway from this project is the significant effort needed to troubleshoot issues in both tablet hardware and application software, and design methodologies for data collection and management that are appropriate for the technology. Although industry and government interests worked cooperatively to field test the technology and troubleshoot bugs, more readily

HIGHLIGHTED OUTCOMES FROM THE 2013 - 2016 CHARTER AND PARTY VESSEL SURVEY

- Industry is now obtaining better information on their catch and where they fish, while taking advantage of reporting efficiencies afforded by mobile technology.

- Data collected to fulfill regulatory reporting requirements can now be used for planning processes. For example, draft maps from the project were utilized in the state of Rhode Island to efficiently address and avoid a marine space conflict where significant charter fishing activity overlapped with a proposed hydrokinetic energy project.

- Lessons learned from the pilot are now being applied to more full-scale deployment on a regional scale.

- Data are being sent to ACCSP ${ }^{1}$

1. Atlantic Coastal Cooperative Statistics Program (www.accsp.org) 


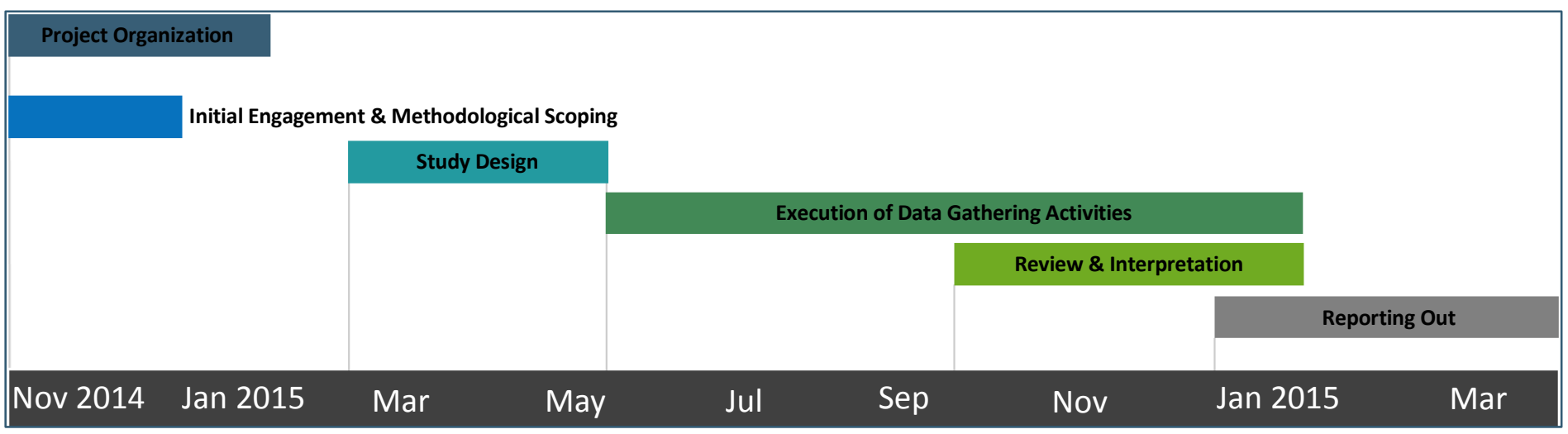

Figure 16. Timeline and duration for the 2013-2016 Charter and Party Vessel Survey. Note that this timeline only captures the second phase of data collection in this project

available training materials would have reduced the effort to train captains and lessen frustration with the systems and errors in the data. Since the initial data collection period, the team has produced a number of short videos to facilitate training and troubleshooting in future efforts. The ability of participants to see the data they are collecting (e.g., view the geographic track of their trips through the application interface) is one possible improvement to the software that would greatly improve the data quality control process, providing a mechanism for participants to identify errors in the data in near real time.

Related to both of these issues is the overall benefit of using a pilot-scale project to build project support and momentum, address technical challenges that inevitably arise when employing new technologies, and showcase how preliminary results can benefit both industry and government partners.

\section{DISCUSSION}

\section{SUMMARY OF LESSONS LEARNED}

The four case studies not only demonstrate the successful applications of the model, but also offer a chance to reflect on overarching lessons learned from the body of work as a whole. By distilling these lessons, we can offer insights on how the best practices associated with the model can be enhanced in future studies.

\section{TIMING MATTERS}

Recreational activities often follow seasonal patterns which must be carefully considered when planning a study. In the case of the 2010 and $2012 \mathrm{MA}$ and NE Boater Surveys, and the 2013 - 2016 Charter and Party Vessel Survey, it was important to calibrate the survey timeline to overlap with the time of year when the majority of activity is likely to occur. In other cases, it may be more prudent to avoid data collection during the height of an activity's season. For example, during the 2015 NE Recreational Use Survey, industry advisors recommended that the team plan participatory mapping exercises in the spring, when the whale watching season has started, but is not in the height of its season. Industry advisors can inform the project team as to which timing strategy is likely to optimize participation in the study.

A related consideration is building in sufficient lead time to account for the inherent and time consuming challenges associated with designing an effective survey instrument and recruiting participants. This lead time is essential to ensure successful and timely launch of the data collection period. Identifying and reaching out to survey participants, vetting the survey tool and questions with advisors, and troubleshooting survey technology can be extremely time-consuming, and each of the studies described in this paper faced timing obstacles related to these tasks. Time projections which anticipate potential bottlenecks and include sufficient buffer time to address unforeseen issues can help to ensure that the data collection period captures sufficient information for the study to meet its objectives.

\section{EXISTING DATA ENHANCES OUTCOMES}

Although data gaps were the impetus for each of the studies described in this paper, there were several examples where using existing datasets improved project 
outcomes. At the outset of a project, it is important for the project team to familiarize itself with existing data sources to determine how the proposed study can improve upon available information. This is important in making the case to project collaborators, advisors, and eventually, survey participants that it is worth their time and effort to contribute to the study and to ensure an efficient study design that does not duplicate existing effort.

The project team can also use existing data to either supplement or ground-truth data collected during the survey. For example, during the 2015 NE Recreational Use Survey, the project team augmented survey data on SCUBA locations by mapping the locations of dive sites described in printed diving guides.

\section{IN-PERSON COMMUNICATION LEADS TO INCREASED PARTICIPATION AND TRUST}

While each of the studies described in this paper relied primarily on data collection technologies not dependent on in-person meetings, the overall efficacy was enhanced by outreach activities that created opportunity for face-toface interaction. These in-person outreach opportunities were intended to encourage participation, supplement data collection, and invite dialogue and feedback on survey results. The best practice of "meeting stakeholders where they are" was evident across this body of work. By this, we mean that a project team should look for opportunities to attend existing meetings, conferences, and other events to recruit participants and vet data. During the 2012 NE Recreational Boater Survey, we presented data at existing meetings held by the boating community (e.g., yacht club meetings). This increased knowledge of, and input into the study, thereby increasing participation in regional ocean planning as a whole.

In some cases, it may also be appropriate to hold inperson meetings that don't take place at existing industry meetings or events. During the 2015 NE Recreational Use Survey, the team led four separate commercial whale watching participatory mapping workshops which resulted in a dataset that was considered to be the most comprehensive of all of the activities mapped during this study. Part of the success of these meetings stemmed from the fact that the meetings were held near geographic "hubs" of whale watch activity, and were therefore relatively convenient for participants. In-person dialogue between whale watch owners and operators, scientists, and non-profits added to the richness of the resulting data and also provided an opportunity for detailed conversations with the project team about the ocean planning process.

Finally, during the recreational fishing study, data collection training and troubleshooting increased face-toface time between the project team and participating captains, providing an opportunity for increased collaboration and trust-building.

Overall, even if a study relies primarily on online or tablet-based data collection tools, building opportunities for in-person interactions with project participants and the stakeholder community at large is critical for the success of a project.

\section{CONCLUSION}

Marine planning initiatives often identify a need for better information about human uses of the ocean and the need to engage stakeholders in the planning process. Sectors that are not well-studied often have the common characteristic of not being heavily regulated. Most recreational activities fall into those categories. This paper explored the benefits of using a collaborative data collection and engagement model for marine human use characterization studies to both fill data gaps and involve industry interests in the planning process. We also explored two key strategies which contributed to the successful completion of marine recreational characterization efforts in the Northeast. "Data as a shared asset" and "tailored engagement approaches" were strategies that were refined and adapted over the course of the projects and contributed to positive project outcomes.

The four case studies demonstrated in different ways how applying these concepts and best practices can result in the development of important marine use data that is understood and trusted by government and industry. In the case studies, we explored how value is created for industry and government by jointly filling important data gaps in ways that have benefits that span individual interests. Importantly, the collaborative data and engagement model and the process to jointly develop marine use data to better understand human behavior 
patterns in our coastal and ocean waters helped to engage industry interests in the marine planning process. Instead of just requesting information by industry or soliciting industry input into a predefined process or data product, this approach to engagement and data gathering offers a more inclusive and interactive framework for involving industry and government in the marine planning process. In addition, industry stakeholders develop trust in and ownership of the plan because they see themselves in the plan and made personal contributions to develop plan data.

A key outcome in the use of such approaches is the substantial social capital that is generated by all parties involved in the process. This capital will be important as marine planning efforts shift from completion of firstgeneration regional plans in the Northeast and MidAtlantic regions to plan implementation activities, future plan updates, and as other regions and locations, seeing value in pursuing marine planning initiatives, embark on similar activities. 


\section{REFERENCES}

Bloeser, J., C. Chen, M. Gates, A. Lipsky, and K. Longley-Wood. Characterization of Coastal and Marine Recreational Activity in the U.S. Northeast. 2015.

Eastern Research Group (ERG). A Review and Summary of Human Use Mapping in the Marine and Coastal Zone. Conducted for NOAA Coastal Services Center, Charleston, SC. 2010.

Hellin, D., K. Starbuck, D. Terkla, A. Roman, and C. Watson. 2010 Massachusetts Recreational Boater Survey. 2011.

Massachusetts Ocean Management Plan. Massachusetts Executive Office of Energy and Environmental Affairs. 2009, 2015.

National Ocean Economics Program (NOEP). State of the U.S. Ocean and Coastal Economies 2009. 2009.

National Ocean Economics Program (NOEP). State of the U.S. Ocean and Coastal Economies 2014. 2014.

National Ocean Economics Program (NOEP). State of the U.S. Ocean and Coastal Economies 2016. 2016.

NOAA Office for Coastal Management. Guidebook to Participatory Mapping of Ocean Uses. Charleston, SC. 2014.

NOAA Science Advisory Board. Integrating Social Science into NOAA Planning, Evaluation and Decision Making: A Review of Implementation to Date and Recommendations for Improving Effectiveness: A Report from the NOAA Science Advisory Board. Silver Spring, MD. 2009.

Pomeroy, R. and F. Douvere. "The engagement of stakeholders in the marine spatial planning process." Marine Policy 32 (2008). 816-822. doi:10.1016/j.marpol.2008.03.017.

Rhode Island Coastal Resources Management Council (CRMC). Rhode Island Ocean Special Area Management Plan. Wakefield, RI. 2010.

SeaPlan. 2015 Pilot Party and Charter Vessel Mapping Study. 2016.

Starbuck, K. and A. Lipsky. 2012 Northeast Recreational Boater Survey: A Socioeconomic and Spatial Characterization of Recreational Boating in Coastal and Ocean Waters of the Northeast United States. 2013.

The White House Council on Environmental Quality (CEQ). Final Recommendations of the Interagency Ocean Policy Task Force. 2010. 